\section{(6) OPEN ACCESS}

\title{
Predicting respiratory hospital admissions in young people with cerebral palsy
}

\author{
Amanda Marie Blackmore, ${ }^{1}$ Natasha Bear, ${ }_{1}^{2,3}$ Eve Blair, ${ }_{1}^{4}$ Katherine Langdon, ${ }^{5,6}$ \\ Lisa Moshovis, ${ }^{1}$ Kellie Steer, ${ }^{7}$ Andrew C Wilson ${ }^{4,6,8}$
}

\begin{abstract}
- Additional material is published online only. To view please visit the journal online (http://dx.doi.org/10.1136/ archdischild-2017-314346).
\end{abstract}

For numbered affiliations see end of article.

\section{Correspondence to}

Dr Amanda Marie Blackmore, Therapy and Health Services, Ability Centre, Mount Lawley, WA 6929, Australia; marie.blackmore@abilitycentre. com.au

Received 23 October 2017 Revised 8 February 2018 Accepted 22 February 2018 Published Online First 19 March 2018

\section{Linked}

- http://dx.doi.org/10.1136/ archdischild-2017-314098

- http://dx.doi.org/10.1136/ archdischild-2018-315134

Check for updates

To cite: Blackmore AM,

Bear N, Blair E, et al.

Arch Dis Child

2018:103:1119-1124.

\section{ABSTRACT}

Objective To determine the early predictors of respiratory hospital admissions in young people with cerebral palsy (CP).

Design A 3-year prospective cohort study using linked data.

Patients Children and young people with CP, aged 1 to 26 years.

Main outcome measures Self-reported and carerreported respiratory symptoms were linked to respiratory hospital admissions (as defined by the International Statistical Classification of Diseases and Related Health Problems 10th Revision codes) during the following 3 years. Results 482 participants (including 289 males) were recruited. They were aged 1 to 26 years (mean 10 years, 10 months; SD 5 years, 11 months) at the commencement of the study, and represented all Gross Motor Function Classification Scale (GMFCS) levels. During the 3-year period, 55 (11.4\%) participants had a total of 186 respiratory hospital admissions, and spent a total of 1475 days in hospital. Statistically significant risk factors for subsequent respiratory hospital admissions over 3 years in univariate analyses were GMFCS level V, at least one respiratory hospital admission in the year preceding the survey, oropharyngeal dysphagia, seizures, frequent respiratory symptoms, gastro-oesophageal reflux disease, at least two courses of antibiotics in the year preceding the survey, mealtime respiratory symptoms and nightly snoring.

Conclusions Most risk factors for respiratory hospital admissions are potentially modifiable. Early identification of oropharyngeal dysphagia and the management of seizures may help prevent serious respiratory illness. One respiratory hospital admission should trigger further evaluation and management to prevent subsequent respiratory illness.

\section{INTRODUCTION}

For individuals with cerebral palsy (CP), respiratory disease is the leading cause of premature death ${ }^{12}$ and a major cause of hospitalisations. ${ }^{3-5}$ This situation has altered very little in the past 40 years. ${ }^{12}$ In order to improve respiratory health in this population, individuals at risk of severe respiratory disease must be identified before irreversible lung damage occurs.

With a view to this, we have previously described self-reported or carer-reported respiratory symptoms and comorbidities for young people with CP, and investigated how these related to respiratory hospitalisations. We found a range of factors, several of which suggested that individuals with oromotor dysfunction leading to recurrent aspiration are at risk

\section{What is already known on this topic?}

- Individuals with cerebral palsy (CP), who are classified as Gross Motor Function Classification System level V, have an increased risk of respiratory illness.

- Respiratory hospital readmission rates for children with $\mathrm{CP}$ are high.

- Oropharyngeal dysphagia is associated with respiratory illness in children with $\mathrm{CP}$.

\section{What this study adds?}

- Individuals with CP who have oropharyngeal dysphagia, seizures, frequent respiratory symptoms, gastro-oesophageal reflux disease and nightly snoring are at risk of future respiratory hospitalisations.

- Most risk factors in young people with CP for future respiratory hospital admissions are potentially modifiable.

- Previous respiratory illnesses (as indicated by hospital admissions or multiple courses of antibiotics) indicate risk of future respiratory hospital admissions.

of respiratory hospitalisations. ${ }^{6}$ These conclusions agree with evidence from other authors linking poor swallowing and aspiration to respiratory illnesses in children with neurological conditions. ${ }^{7-10}$

Our previous study was limited by its reliance on self-reported data for hospitalisations and its cross-sectional design. Prospective longitudinal data are required to provide evidence regarding the development of respiratory disease. ${ }^{11}$ In this paper, using linked hospital morbidity data, we investigate associations between respiratory symptoms in the cohort who completed our initial survey and respiratory hospitalisations during the following 3 years. Our objective was to determine the early predictors of respiratory hospital admissions.

\section{METHOD}

\section{Participants}

This was a prospective cohort study. All individuals with CP in Western Australia under 27 years of age were eligible to participate. According to the state CP register, 1942 individuals with CP were born from 1986 to 2011. Allowing for some mortality, the original cohort $(n=551)$ represented about a third of the eligible population. Between November 
2011 and June 2012, a survey described previously ${ }^{6} 12$ was completed by competent participants aged 18 years and over, and by parents or carers of children with CP under 18 years and of adults with CP unable to complete the survey themselves. Out of 551 participants who completed the survey, 482 gave written consent to link the survey data to the Hospital Morbidity Data Collection of the Western Australian Health Department.

\section{Predictor variables}

The survey obtained self-reported or parent/carer-reported measures of the following variables: oropharyngeal dysphagia; number of frequent respiratory symptoms (coughing daily, sounding chesty or phlegmy weekly, and sounding wheezy weekly); snoring at least every night; respiratory symptoms (gurgly voice, wheezing, coughing, sneezing, choking) during meals; presence or history of gastro-oesophageal reflux disease (GORD); presence of seizures; diagnosis of scoliosis; current asthma; presence of smoker in the household; number of hospitalisations in the 12 months preceding completion of the survey; sex; and Gross Motor Function Level, as determined by the Gross Motor Function Classification Scale (GMFCS). ${ }^{13}$ The GMFCS Family Report Questionnaires were used up to age 12 years, and the GMFCS Expanded and Revised Descriptors and Illustrations for Children between Their 12th and 18th Birthdays were used for older participants. Oropharyngeal dysphagia was operationally defined as: (A) use of a gastro-oesophageal tube and/or food or drink texture modifications, and/or (B) coughing or choking on saliva. See online supplementary appendix for response options and coding of these variables.

\section{Hospital admissions}

The Hospital Morbidity Data Collection lists all (public and private) hospital admissions for all causes. For this study, we selected respiratory hospital admissions in the 12 months preceding and the 36 months following the date of completion of each individual's survey. The outcome measures were number of admissions and length of stay using International Statistical Classification of Diseases and Related Health Problems 10th Revision (ICD-10) codes (J00-J99 and R06, excluding J30-J39, which refer to tonsillitis and laryngitis) as either primary or additional diagnoses. Up to 10 additional diagnoses were possible. Probabilistic linkage was performed by the Western Australian Data Linkage Unit using full name, full date of birth and address.

\section{Statistical analyses}

Frequencies and proportions were calculated. Hospital admission rates were defined as number of hospital admissions (including multiple admissions for the same individual) divided by the number of individuals. This was performed cumulatively for 1, 2 and 3 years following the survey.

Incidence rate ratios (IRR) and their 95\% CIs were determined using negative binomial models as the data were overdispersed. An exposure variable was incorporated, deducting time in hospital for any admissions and accounting for any participants who had died. Initially, univariate testing was conducted. A multivariable model was then created through purposeful selection of covariates using backwards elimination. ${ }^{14}$ Contribution to the model was assessed by examining the Wald statistic for each variable and reviewing the impact of the variable on the other estimated coefficients. A change in any remaining coefficient of more than $25 \%$ was considered to be a confounding change, and it was retained in the model.

Multiple imputations by chained equations (MICE) were used to manage missing data. There were 58 missing values for 15 predictor variables. Data were missing for the following variables: snoring (3.5\%), respiratory signs with meals $(0.4 \%)$, seizures $(1.7 \%)$, coughing and choking on saliva (2.3\%), scoliosis $(3.5 \%)$ and antibiotic use $(0.6 \%)$. A complete case analysis would have yielded a sample size of 432 participants, whereas MICE allowed inclusion of all consenting participants $(n=482)$. In total, 10 data sets were imputed.

Statistical significance level was set at $p<0.05$. All statistical analyses were performed using Stata V.14.1 (StataCorp, College Station, Texas).

\section{RESULTS}

\section{Rates of respiratory hospital admissions and readmissions}

The cohort was 482 participants (289 males) with a mean age of $10.8(\mathrm{SD}=5.9)$ years (median $=10.0 ; \mathrm{IQR}=6-15)$ at the beginning of the study. The GMFCS distribution in the sample was similar to the GMFCS distribution in the CP population ${ }^{15}$ (see table 1). In the 3 years following the survey, there were 11 $(2.3 \%)$ deaths; and 55 (11.4\%) individuals had 186 respiratory hospital admissions (totalling 1475 days in hospital), of whom $125(67.2 \%)$ had a primary and $61(32.8 \%)$ a secondary respiratory diagnosis. Where the respiratory diagnosis was secondary, the most common primary diagnosis was seizure related $(n=32)$. The rates of admission in the first year, the first 2 years and the 3 years were $17.0,27.0$ and 38.6 per 100 participants, respectively. Most (61.8\%) of the 55 individuals had a respiratory hospitalisation in the first year.

Readmission rates were high: 48\% admitted in the year preceding the survey were readmitted in year 1 following the survey; 35\% admitted in year 1 were readmitted in year 2; and $40 \%$ admitted in year 2 were readmitted in year 3 -an average readmission rate of $41 \%$.

\section{Characteristics of individuals with respiratory hospital admissions}

The 55 individuals with hospitalisations had a mean age of 10.8 $(\mathrm{SD}=5.8)$ years at the beginning of the study, and most were male (61.8\%), were classified as GMFCS V (54.5\%) and/or had oropharyngeal dysphagia (80.0\%), GORD (78.2\%), seizures $(69.1 \%)$ and/ or respiratory symptoms with meals $(67.3 \%)$ (table 1$)$.

\section{Univariate predictors of respiratory hospital admissions}

Univariate regression results (table 2) indicated that the risk factors significantly associated with increased respiratory hospitalisation rates were: GMFCS V classification, at least one respiratory hospitalisation in the year preceding the survey, oropharyngeal dysphagia, seizures, number of frequent respiratory symptoms, GORD, two or more courses of antibiotics in the year preceding the survey, respiratory symptoms with meals and nightly snoring.

\section{Multivariable predictors of respiratory hospital admissions}

The multivariable model (table 3) retained as significant the following risk factors: at least one respiratory hospitalisation in the year preceding the survey, oropharyngeal dysphagia, seizures, nightly snoring (except at 1 year) and GORD. GORD was retained in the model in all years; it did not make a statistically significant contribution at year 1 , but its influence on the IRR for oropharyngeal dysphagia warranted its inclusion across all years. No interaction terms were significant.

\section{DISCUSSION}

This study identified carer-reported or self-reported predictors of future respiratory hospital admissions over 3 years in young people with CP. Six of the factors are potentially modifiable: oropharyngeal dysphagia, respiratory symptoms with meals, 


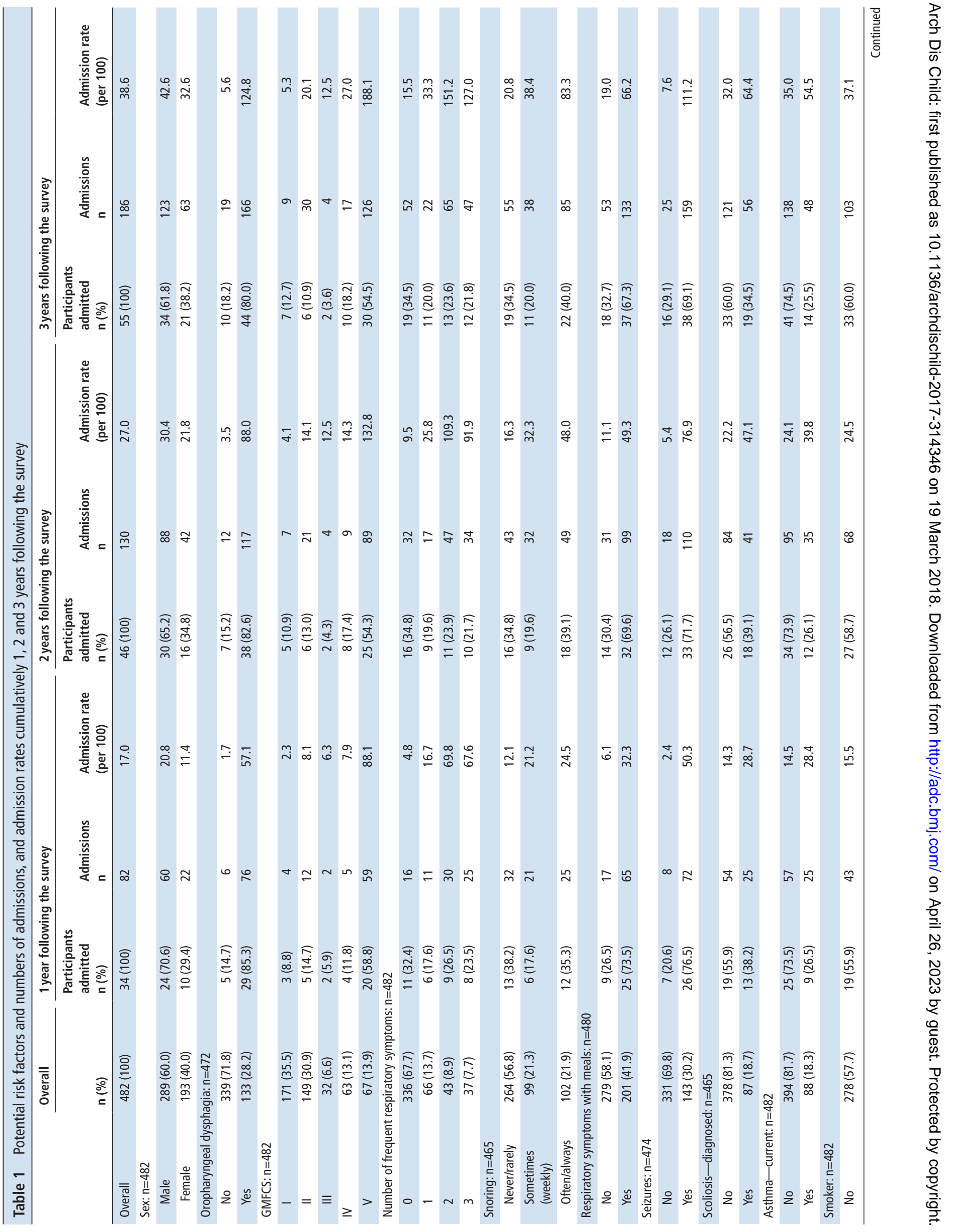




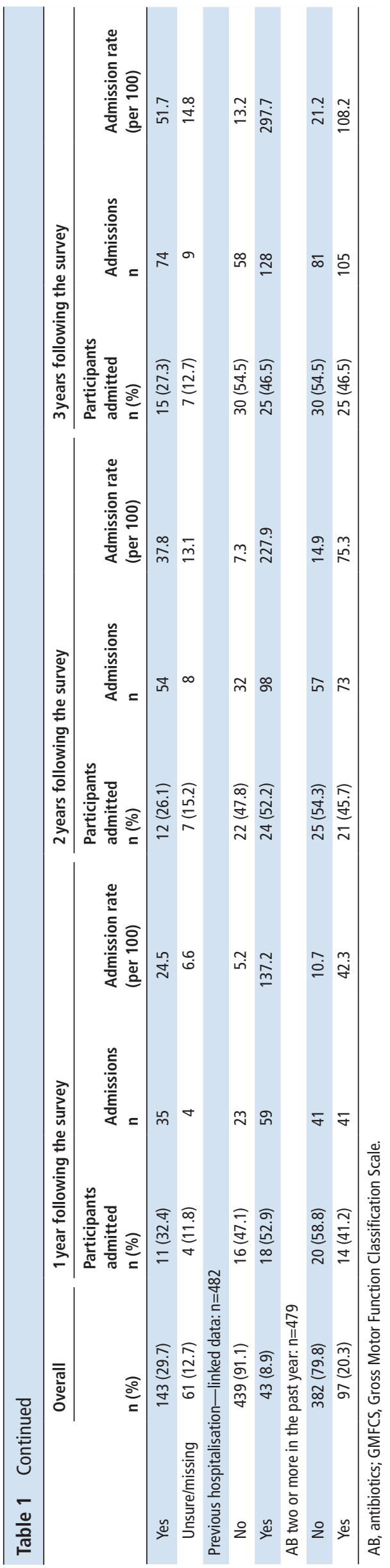

seizures, frequent respiratory symptoms, GORD and nightly snoring. The other three are non-modifiable markers of risk that should alert clinicians, and trigger evaluation and management of modifiable risk factors: GMFCS V classification, at least one respiratory admission in the previous year, and two or more courses of antibiotics in the previous year.

The strongest modifiable risk factor for respiratory hospitalisations was oropharyngeal dysphagia. This was defined as nutritional intake via a tube and/or use of modified textures and/or reported choking or coughing on saliva. These symptoms indicate motor or sensory dysfunction at the oropharyngeal level, affecting the ability to prepare and manipulate a bolus or secretions, and to coordinate breathing and swallowing, resulting in dysphagia and potential chronic aspiration. Presence of respiratory symptoms with meals (gurgly voice, wheezing, coughing, sneezing, choking) also predicted respiratory hospitalisations in univariate analysis. These mealtime symptoms should trigger comprehensive assessment of oropharyngeal dysphagia. Early identification and management of oropharyngeal dysphagia may prevent or delay serious respiratory disease in this population.

Presence of any two of three frequent respiratory symptoms (coughing daily, sounding chesty or phlegmy weekly, and/or sounding wheezy weekly) indicated significantly heightened risk of subsequent respiratory hospitalisations. These symptoms suggest lower respiratory tract infection or inflammation and may result from oropharyngeal dysphagia and consequent aspiration. Recent evidence suggests that chronic aspiration may be associated with chronic airway inflammation and infection with Pseudomonas aeruginosa and other bacteria in children with $\mathrm{CP} .{ }^{16}$ Children with ongoing respiratory symptoms may therefore benefit from antibiotic therapy specifically targeted at $P$. aeruginosa or prophylaxis with broad spectrum oral antibiotics. This approach is commonly used in children with other suppurative lung diseases such as cystic fibrosis and bronchiectasis. ${ }^{17}$ Routine immunisation against influenza is recommended for young people with chronic respiratory disease, and may also benefit individuals with $\mathrm{CP}$ at risk of respiratory disease.

Respiratory symptoms were identified as risk factors, but a current diagnosis of asthma was not. A trial of asthma medications such as bronchodilators or inhaled corticosteroids may be considered for individuals with persistent wheezing. However, symptoms attributed to asthma may result from other pathology, particularly aspiration, and so asthma medications should be continued only if there is evidence of a significant response. ${ }^{18}$

There is preliminary evidence that some physiotherapy interventions may be beneficial for children with $\mathrm{CP}^{19-21}$ Controlled trials are required to establish the appropriate place for physiotherapy in children with $\mathrm{CP}$ at risk of respiratory disease.

Presence of current seizures is a risk factor for subsequent respiratory hospitalisations. Its contribution is probably multifactorial. The motor activity, altered muscle tone and the reduced level of consciousness during and following seizures may worsen oropharyngeal dysphagia and GORD, increasing risk of aspiration. In addition, medications for emergency seizure management, such as benzodiazepines, may increase salivary production and cause drowsiness, exacerbating oropharyngeal dysphagia. Optimising seizure control may ameliorate risk of serious respiratory illness.

GORD was a risk factor, but there is little published evidence to suggest that management of GORD decreases respiratory illness in CP. Indeed, one study found that individuals who had antireflux surgery were more likely to be colonised with lower respiratory tract pathogens. ${ }^{16}$ Nevertheless, simple measures to prevent reflux, such as appropriate positioning during and after meals and smaller, more frequent meals, may be beneficial. 
Table 2 Univariate analysis (negative binomial model) producing IRRs and their $95 \%$ Cls for number of admissions cumulatively 1, 2 and 3 years following the survey

\begin{tabular}{|c|c|c|c|}
\hline \multirow[b]{2}{*}{ Predictor } & \multicolumn{3}{|c|}{ IRRs for hospitalisations following the questionnaire ( $95 \% \mathrm{Cls})$} \\
\hline & 1 year & 2 years & 3 years \\
\hline Sex (female) $\dagger$ & $0.65(0.230$ to 1.81$)$ & 0.85 (0.330 to 2.17$)$ & $0.88(0.352$ to 2.19$)$ \\
\hline Oropharyngeal dysphagia†‡§ & $38.4(14.1 \text { to } 105)^{*}$ & $30.2(13.4 \text { to } 68)^{*}$ & $31.1(14.7 \text { to } 66)^{*}$ \\
\hline \multicolumn{4}{|l|}{ GMFCS†‡§ } \\
\hline 1 & 1.00 & 1.00 & 1.00 \\
\hline$\|$ & $3.58(0.98$ to 13.1$)$ & $3.61(1.22 \text { to } 10.6)^{*}$ & $4.1(1.51 \text { to } 11.3)^{*}$ \\
\hline III & $2.67(0.352$ to 20.2$)$ & $3.06(0.57$ to 16.3$)$ & $2.38(0.46$ to 12.5$)$ \\
\hline IV & $3.44(0.72$ to 16.4$)$ & $3.63(0.97$ to 13.6$)$ & $5.6(1.75 \text { to } 19.5)^{*}$ \\
\hline V & $48(12.9 \text { to } 179)^{*}$ & $49(15.3 \text { to } 156)^{*}$ & $60(19.7 \text { to } 184)^{*}$ \\
\hline \multicolumn{4}{|l|}{ Number of frequent respiratory symptoms $† \S \S$} \\
\hline 0 & 1.00 & 1.00 & 1.00 \\
\hline 1 & $3.32(1.02 \text { to } 10.8)^{*}$ & 2.51 (0.83 to 7.63$)$ & 2.01 (0.66 to 6.07$)$ \\
\hline 2 & $15.7(4.6 \text { to } 54)^{*}$ & $13.4(3.95 \text { to } 45)^{*}$ & $12.4(3.57 \text { to } 43)^{*}$ \\
\hline 3 & $18.4(4.7 \text { to } 72)^{*}$ & $15.6(4.0 \text { to } 62)^{*}$ & $14.7(3.61 \text { to } 60)^{*}$ \\
\hline \multicolumn{4}{|l|}{ Snoring $\neq \S$} \\
\hline Never/rarely & 1.00 & 1.00 & 1.00 \\
\hline Sometimes (weekly) & 1.68 (0.47 to 5.9$)$ & 2.00 (0.63 to 6.3$)$ & $2.03(0.67 \text { to } 6.2)^{*}$ \\
\hline Often/always & $1.96(0.56$ to 6.8$)$ & $2.51(0.82$ to 7.7$)$ & $3.25(1.11 \text { to } 9.5)^{*}$ \\
\hline Respiratory symptoms with meals $† \S$ & $5.9(2.30 \text { to } 15.1)^{*}$ & $5.5(2.34 \text { to } 13.1)^{*}$ & $4.6(1.99 \text { to } 10.8)^{*}$ \\
\hline GORDt‡§ & $7.3(2.78 \text { to } 17.8)^{*}$ & $8.0(3.67 \text { to } 19.7)^{*}$ & $7.4(3.24 \text { to } 16.9)^{*}$ \\
\hline Seizurest‡§ & $24.3(9.3 \text { to } 63)^{*}$ & $18.3(8.1 \text { to } 42)^{*}$ & $21.3(9.9 \text { to } 46)^{\star}$ \\
\hline Scoliosist‡§ & 2.34 (0.64 to 8.5$)$ & 2.50 (0.77 to 8.2$)$ & 2.38 (0.74 to 7.7$)$ \\
\hline Asthma-current $\dagger$ & 2.24 (0.64 to 7.9$)$ & 1.95 (0.59 to 6.4$)$ & $1.8(0.57$ to 5.9$)$ \\
\hline \multicolumn{4}{|l|}{ Smoker§ } \\
\hline No & 1.00 & 1.00 & 1.00 \\
\hline Yes & 1.60 (0.55 to 4.6$)$ & $1.72(0.64$ to 4.6$)$ & 1.70 (0.65 to 4.4$)$ \\
\hline Unsure/missing & 0.369 (0.069 to 1.99$)$ & 0.44 (0.102 to 1.91$)$ & $0.31(0.075$ to 1.29$)$ \\
\hline $\begin{array}{l}\text { At least one respiratory hospital admission in the } \\
\text { year preceding the survey } \neq \S\end{array}$ & $33.8(13.7 \text { to } 83)^{*}$ & $46(20.6 \text { to } 101)^{*}$ & $37.6(14.72 \text { to } 96)^{*}$ \\
\hline $\begin{array}{l}\text { Two or more courses of antibiotics in the year } \\
\text { preceding the survey } \ddagger \S\end{array}$ & $4.6(1.52 \text { to } 13.9)^{*}$ & $5.4(1.97 \text { to } 15.0)^{*}$ & $5.4(1.98 \text { to } 14.6)^{*}$ \\
\hline
\end{tabular}

GMFCS, Gross Motor Function Classification Scale; GORD, gastro-oesophageal reflux disease; IRR, incidence rate ratio.

tIncluded in initial multivariate model for 1 year $(p<0.25)$.

łIncluded in initial multivariate model for 2 year $(\mathrm{p}<0.25)$.

§Included in initial multivariate model for 3 year $(p<0.25)$

Nightly snoring was a risk factor for respiratory hospitalisations. The mechanism for this is uncertain. Snoring may reflect hypotonia and discoordination of upper airway muscles, and hence increase risk of aspiration. Alternatively, the increased work of breathing associated with snoring may increase the risk of gastro-oesophageal reflux and aspiration. ${ }^{22}$ Furthermore, minor respiratory infections may increase nocturnal work of breathing and upper airway obstruction (both awake and asleep) in snoring individuals. Snoring was common in this population, and it is reasonable to consider assessment and management of obstructive sleep apnoea.

A GMFCS V classification is a non-modifiable risk factor, but was the strongest predictor of respiratory hospitalisations in univariate analyses. Young people with CP classified as functioning at level $\mathrm{V}$ GMFCS had a much higher risk of admissions than all other

Table 3 Multivariable analysis model (negative binomial model) producing IRRs and their $95 \%$ Cls for number of admissions cumulatively 1,2 and 3 years following the survey

Multivariable regressiont-negative binomial model

Incidence rate ratios for hospitalisations following the questionnaire $(95 \% \mathrm{Cls})$

\begin{tabular}{|c|c|c|c|}
\hline \multirow{2}{*}{ Predictor } & \\
\hline & 1 year & 2 years & 3 years \\
\hline Oromotor dysfunction & $8.8(3.01 \text { to } 25.7)^{*}$ & $7.1(2.81 \text { to } 17.9)^{*}$ & $6.4(2.86 \text { to } 14.2)^{*}$ \\
\hline \multicolumn{4}{|l|}{ Snoring } \\
\hline Never/rarely & & 1.00 & 1.00 \\
\hline Sometimes (weekly) & & 1.26 (0.50 to 3.16$)$ & 1.59 (0.67 to 3.76$)$ \\
\hline Often/always & & $2.57(1.15 \text { to } 5.7)^{*}$ & $3.73(1.77 \text { to } 7.9)^{*}$ \\
\hline GORD & $1.77(0.73$ to 4.3$)$ & $3.61(1.59 \text { to } 8.2)^{*}$ & $3.00(1.46 \text { to } 6.2)^{*}$ \\
\hline Seizures & $3.59(1.35 \text { to } 9.6)^{*}$ & $3.20(1.38 \text { to } 7.4)^{*}$ & $3.96(1.9 \text { to } 8.3)^{*}$ \\
\hline Previous hospitalisation—linked data & $12.9(5.7 \text { to } 29.1)^{*}$ & $16.2(7.8 \text { to } 33.4)^{*}$ & $13.8(6.8 \text { to } 28.3)^{*}$ \\
\hline
\end{tabular}

${ }^{*} \mathrm{P}<0.05$ (bold).

†Multivariable model adjusted for covariates listed.

GORD, gastro-oesophageal reflux disease; IRR, incidence rate ratio. 
GMFCS levels. GMFCS V classification was a good predictor of respiratory hospitalisations partly because of its strong association with oropharyngeal dysphagia, ${ }^{6}$ and possibly because of the greater burden of comorbidities in young people classified as GMFCS V. ${ }^{23}$

Previous respiratory infections, as indicated by previous hospitalisations or courses of antibiotics, marked an increased risk of subsequent hospitalisations, which is consistent with previous research. ${ }^{24}$ The incidence rate for those with at least one respiratory hospitalisation in the year preceding the survey was 10 times greater than for those with none. Such admissions should be seen as a red flag indicating that an individual may require evaluation and management to prevent subsequent respiratory hospitalisations.

Scoliosis was not a statistically significant predictor. Although scoliosis often coexists with respiratory disease at the time of death in people with $\mathrm{CP},{ }^{1}$ our data suggest that scoliosis does not precede or cause the respiratory illness.

\section{Limitations}

The sample did not include the full population, but its GMFCS distribution closely reflects the CP population and all age levels within the intended age range were represented. Frequency of respiratory illness is likely to be underestimated in this study because: (A) ICD-10 coding may underestimate the prevalence of respiratory diagnoses, ${ }^{15}$ and (B) hospital admission occurs in only $57 \%$ of children with CP presenting to hospital emergency departments with respiratory symptoms. ${ }^{16}$

The 3-year follow-up period of this study cannot indicate how many individuals develop respiratory illness in later life. Mobility declines with age in moderate and severe CP, and so may swallowing difficulties. ${ }^{25}{ }^{26}$ Risk of respiratory disease may increase correspondingly.

\section{CONCLUSIONS}

Evidence from this study may be used to identify children and young people with CP at risk of future respiratory hospital admissions. Most of these risk factors are potentially modifiable. Identification of children and young people with CP with unmodifiable risks, such as previous respiratory hospitalisations and GMFCS V classification, should prompt evaluation of potentially modifiable risks, such as oropharyngeal dysphagia, seizures and GORD.

\author{
Author affiliations \\ 'Therapy and Health Services, Ability Centre, Mount Lawley, Western Australia, \\ Australia \\ ${ }^{2}$ Physiotherapy, Princess Margaret Hospital for Children, Perth, Western Australia, \\ Australia \\ ${ }^{3}$ Department of Clinical Research and Education, Child Adolescent Health Service, \\ Subiaco, Western Australia, Australia \\ ${ }^{4}$ Telethon Kids Institute, The University of Western Australia, Subiaco, Western \\ Australia, Australia \\ ${ }^{5}$ Paediatric Rehabilitation, Princess Margaret Hospital for Children, Subiaco, Western \\ Australia, Australia \\ ${ }^{6}$ School of Paediatrics and Child Health, The University of Western Australia, Crawley, \\ Western Australia, Australia \\ ${ }^{7}$ Organisational Effectiveness Unit, Ramsay Health Care, Joondalup, Western \\ Australia, Australia \\ ${ }^{8}$ Respiratory Medicine, Princess Margaret Hospital for Children, Subiaco, Western \\ Australia, Australia
}

Acknowledgements We gratefully acknowledge the contribution of the participants in this study. We thank the staff at the Western Australian Data Linkage Branch and the Hospital Morbidity Data Collection. We also thank Linda Watson for her advice on CP population data.

Funding The initial survey was funded by Health Networks Funding from the Western Australian Health Department. Analysis of the linked data was funded by individual donations to the Ability Centre and by Non-Government Centre Support.

Competing interests None declared.
Ethics approval Princess Margaret Hospital for Children Ethics Committee and the Department of Health Western Australian Human Research Ethics Committee.

Provenance and peer review Not commissioned; externally peer reviewed. Data sharing statement Additional unpublished data from the study are not available.

Open access This is an open access article distributed in accordance with the Creative Commons Attribution Non Commercial (CC BY-NC 4.0) license, which permits others to distribute, remix, adapt, build upon this work non-commercially, and license their derivative works on different terms, provided the original work is properly cited, appropriate credit is given, any changes made indicated, and the use is non-commercial. See: http://creativecommons.org/licenses/by-nc/4.0/.

(C) Article author(s) (or their employer(s) unless otherwise stated in the text of the article) 2018. All rights reserved. No commercial use is permitted unless otherwise expressly granted.

\section{REFERENCES}

1 Himmelmann K, Sundh V. Survival with cerebral palsy over five decades in western Sweden. Dev Med Child Neurol 2015;57:762-7.

2 Reid SM, Carlin JB, Reddihough DS. Survival of individuals with cerebral palsy born in Victoria, Australia, between 1970 and 2004. Dev Med Child Neurol 2012;54:353-60.

3 Meehan E, Reid SM, Williams K, et al. Hospital admissions in children with cerebral palsy: a data linkage study. Dev Med Child Neurol 2017;59:512-9.

4 Murphy NA, Hoff C, Jorgensen T, et al. Costs and complications of hospitalizations for children with cerebral palsy. Pediatr Rehabil 2006;9:47-52.

5 Young NL, McCormick AM, Gilbert T, et al. Reasons for hospital admissions among youth and young adults with cerebral palsy. Arch Phys Med Rehabil 2011;92:46-50.

6 Blackmore AM, Bear N, Blair E, et al. Factors associated with respiratory illness in children and young adults with cerebral palsy. J Pediatr 2016;168:151-7.

7 Benfer KA, Weir KA, Ware RS, et al. Parent-reported indicators for detecting feeding and swallowing difficulties and undernutrition in preschool-aged children with cerebral palsy. Dev Med Child Neurol 2017;59:1181-7.

8 Morton RE, Wheatley R, Minford J. Respiratory tract infections due to direct and reflux aspiration in children with severe neurodisability. Dev Med Child Neurol 1999:41:329-34.

9 Taniguchi MH, Moyer RS. Assessment of risk factors for pneumonia in dysphagic children: significance of videofluoroscopic swallowing evaluation. Dev Med Child Neurol 1994:36:495-502.

10 Weir KA, McMahon S, Taylor S, et al. Oropharyngeal aspiration and silent aspiration in children. Chest 2011;140:589-97.

11 Reid SM. Improving survival in cerebral palsy: where do we go from here? Dev Med Child Neurol 2015:57:703-4.

12 Blackmore AM, Bear N, Blair E, et al. Prevalence of symptoms associated with respiratory illness in children and young people with cerebral palsy. Dev Med Child Neurol 2016;58:780-1.

13 Palisano R, Rosenbaum P, Walter $\mathrm{S}$, et al. Development and reliability of a system to classify gross motor function in children with cerebral palsy. Dev Med Child Neurol 1997;39:214-23.

14 Hosmer DW, Lemeshow S. Applied logistic regression. New York: John Wiley and Sons, 2000.

15 Reid SM, Carlin JB, Reddihough DS. Using the gross motor function classification system to describe patterns of motor severity in cerebral palsy. Dev Med Child Neurol 2011;53:1007-12.

16 Gerdung CA, Tsang A, Yasseen AS, et al. Association between chronic aspiration and chronic airway infection with Pseudomonas aeruginosa and other gram-negative bacteria in children with cerebral palsy. Lung 2016;194:307-14.

17 Hnin K, Nguyen C, Carson KV, et al. Prolonged antibiotics for non-cystic fibrosis bronchiectasis in children and adults. Cochrane Database Syst Rev 2015:CD001392.

18 Fitzgerald DA, Follett J, Van Asperen PP. Assessing and managing lung disease and sleep disordered breathing in children with cerebral palsy. Paediatr Respir Rev 2009;10:18-24.

19 Garuti G, Verucchi E, Fanelli I, et al. Management of bronchial secretions with Free Aspire in children with cerebral palsy: impact on clinical outcomes and healthcare resources. Ital J Pediatr 2016;42:7.

20 Lagerkvist AL, Sten G, Westerberg B, et al. Positive expiratory pressure (PEP) treatment in children with multiple severe disabilities. Acta Paediatr 2005;94:538-42.

21 Yuan N, Kane P, Shelton K, et al. Safety, tolerability, and efficacy of high-frequency chest wall oscillation in pediatric patients with cerebral palsy and neuromuscular diseases: an exploratory randomized controlled trial. J Child Neurol 2010;25:815-21.

22 Noronha AC, de Bruin VM, Nobre e Souza MA, et al. Gastroesophageal reflux and obstructive sleep apnea in childhood. Int J Pediatr Otorhinolaryngol 2009;73:383-9.

23 Shevell MI, Dagenais L, Hall N. Comorbidities in cerebral palsy and their relationship to neurologic subtype and GMFCS level. Neurology 2009;72:2090-6.

24 Meehan E, Freed GL, Reid SM, et al. Tertiary paediatric hospital admissions in children and young people with cerebral palsy. Child Care Health Dev 2015;41:928-37.

25 Benner JL, Hilberink SR, Veenis T, et al. Long-term deterioration of perceived health and functioning in adults with cerebral palsy. Arch Phys Med Rehabil 2017;98:2196-205.

26 Haak P, Lenski M, Hidecker MJ, et al. Cerebral palsy and aging. Dev Med Child Neurol 2009:51(Suppl 4):16-23. 


\section{Correction: Predicting respiratory hospital admissions in young people with cerebral palsy}

Blackmore AM, Bear N, Blair E, et al. Predicting respiratory hospital admissions in young people with cerebral palsy. Arch Dis Child 2018;103:1119-24.

In this article, page 1120 , column 2 , line 17 , the number of deaths should read 10 , not 11 . The eleventh death occurred in the sixth month after the end of the study period.

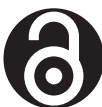

\section{OPEN ACCESS}

Open access This is an open access article distributed in accordance with the Creative Commons Attribution Non Commercial (CC BY-NC 4.0) license, which permits others to distribute, remix, adapt, build upon this work noncommercially, and license their derivative works on different terms, provided the original work is properly cited, appropriate credit is given, any changes made indicated, and the use is non-commercial. See: http://creativecommons.org/licenses/by-nc/ 4.0\%.

(C) Author(s) (or their employer(s)) 2019. Re-use permitted under CC BY-NC. No commercial re-use. See rights and permissions. Published by BMJ.

Arch Dis Child 2019;104:1215. doi:10.1136/archdischild-2017-314346corr1

A) Check for updates 